\title{
Green Biosynthesized Selenium Nanoparticles by Cinnamon Extract and Their Antimicrobial Activity and Application as Edible Coatings with Nano-Chitosan
}

\author{
Mousa A. Alghuthaymi, ${ }^{1}$ Amany M. Diab $\mathbb{D}^{2},{ }^{2}$ Aml F. Elzahy, ${ }^{3}$ Khaled E. Mazrou, ${ }^{4}$ \\ Ahmed A. Tayel $\mathbb{D}^{3}{ }^{3}$ and Shaaban H. Moussa $\mathbb{D D}^{1,5}$ \\ ${ }^{1}$ Department of Biology, College of Science and Humanitarian Studies, Shaqra University, Shaqraa, Saudi Arabia \\ ${ }^{2}$ Department of Aquaculture, Faculty of Aquatic and Fisheries Sciences, Kafrelsheikh University, Kafr el-Sheikh, Egypt \\ ${ }^{3}$ Department of Fish Processing and Biotechnology, Faculty of Aquatic and Fisheries Sciences, Kafrelsheikh University, \\ Kafr el-Sheikh, Egypt \\ ${ }^{4}$ Department of Plant Biotechnology, Genetic Engineering and Biotechnology Research Institute, University of Sadat City, \\ El-Sadat City, Egypt \\ ${ }^{5}$ Department of Microbial Biotechnology, Genetic Engineering and Biotechnology Research Institute, University of Sadat City, \\ El-Sadat City, Egypt
}

Correspondence should be addressed to Shaaban H. Moussa; shaus2008@yahoo.com

Received 23 December 2020; Revised 4 March 2021; Accepted 10 March 2021; Published 18 March 2021

Academic Editor: Laura Arru

Copyright ( 2021 Mousa A. Alghuthaymi et al. This is an open access article distributed under the Creative Commons Attribution License, which permits unrestricted use, distribution, and reproduction in any medium, provided the original work is properly cited.

\begin{abstract}
Bioactive nanocomposites were constructed, containing chitosan (Cht), extracted from shrimps' wastes, and transformed into nanoparticles (NPs) using ionic-gelation. Selenium NPs (Se-NPs) were phytosynthesized using cinnamon (Cinnamomum zeylanicum) bark extract (CIE), characterized and evaluated with Cht-NPs as antimicrobial composites against bacterial foodborne pathogens "Escherichia coli, Salmonella typhimurium, Staphylococcus aureus, and Listeria monocytogenes" and as potential edible coating (EC) basements. The CIE-phytosynthesized Se-NPs had well-distributed and spherical shapes with $23.2 \mathrm{~nm}$ mean diameter. The CIE, CIE/Se-NPs, and innovative CIE/Se/Cht-NP composites exhibited distinguished antibacterial actions toward the entire screened pathogens; CIE/Se/Cht-NP composite was significantly the most potent. The formulated ECs from CIE/Se/ Cht-NP nanocomposites had matching antibacterial manner, which was strengthened with CIE/Se-NP percentage increments. Scanning micrographs indicated the attachment of CIE/Se-NPs to bacterial cells to cause their complete lysis and death after $10 \mathrm{~h}$ of exposure. CIE/Se/Cht-NP composites are proposed as effectual control agents toward food-borne pathogens using efficient biological carriers and eco-friendly phytosynthesis protocol.
\end{abstract}

\section{Introduction}

Chitosan (Cht) is a derivative polysaccharide from deacetylated chitin $(\mathrm{Ct})$, which is the principal constituent of crustacean exoskeleton [1]. Besides, Cht and Ct could present in many insects and fungal cell wall [2]. Cht has reported antimicrobial potentialities toward various microorganisms, e.g., bacteria, fungi, and yeast [3-5], with suggested higher activity against Gram-positive bacteria than Gram-negative species [1]. Cht is an extraordinary costeffective biopolymer with numerous biological and environmental advantages, e.g., its elevated biocompatibility, biodegradability, bioactivity, and biosafety attributes, which advocate wide applications, Cht and their nanoparticles (NPs), in biomedical, nutritional, environmental, and therapeutic aspects [6-8]. The polymer NP formation, e.g., Cht-NPs, was proved to augment the biopolymer bioactivities (such as anticancer, antimicrobial, toxicant 
adsorption, bioremediation, drugs' carrying, nanometals conjugation, and antioxidant and anti-inflammatory attributes, comparing with bulk materials $[6,7,9-12]$.

Selenium (Se), the vital element in biological bodies (as antioxidative and prooxidative agent) has vast significance in nutrition and medicine [13], with narrow ranges between toxic levels and dietary deficiency $(400 \mu \mathrm{g}$ and $40 \mu \mathrm{g} /$ day, respectively).

Se has vital functions in cellular metabolism, enzymes' activation, body protection from free radical species, human fertility, thyroid metabolism, and several additional energetic functions. The Se biological applications were succeeded in diverse fields, e.g., health, biochemistry, genetics, and molecular biology, including its usages in antioxidants, antitumors, enzyme inhibitors, anti-infective, cytokine inducers, and immunomodulator formulations [14]. Se nanoparticles (Se-NPs) have surplus bioactivities than bulk $\mathrm{Se}$ as low-toxicity chemopreventive and bioactive agents [15-19]. Accordingly, Se-NP synthesis via different protocols was extensively investigated for their potential bio-applications $[15,18]$.

Spices were historically employed as effectual natural food-antimicrobial materials and for improving foods' aroma and flavors [20]. With elevated concerns regarding the chemical additives' safety, consumers and researchers are always searching for natural alternatives to preserve and enhance food quality [21]. Herbs, spices, and plants' derivatives were always the perfect candidates to replace synthetic antimicrobial and antioxidant materials [22].

Cinnamon spices are gathered from the bark of Cinnamomum genus trees, which contain $\sim 250$ species, for global utilization in cooking and flavoring and in ethnic and modern medicines [23]. Cinnamomum zeylanicum barks are historical herbal medicines that have numerous curative and food-flavoring attributes [24].

Edible coating (EC) was emerged as promising tool for food preservation and is defined as "the thin layers of materials that cover food surfaces and can be eaten and considered as a part of the whole food product" [25]. The key rationales of EC are to provide supplementary nutrients, quality and sensory enhancers, antimicrobial agents, etc., while consumed on food materials. ECs could additionally act as barriers to exterior threats that endanger food quality (e.g., oxygen, vapors, moisture, and oil) to protect, prevent dehydration, and extend shelf-life of coated foods $[25,26]$. The fabrication of coated metals' nanoparticles with polymer possessed elevated potentialities for application in pharmaceutical, biomedical, environmental, and food-related fields [11, 27-29].

Accordingly, this research intended the extraction and synthesis of Cht-NPs (as bioactive, eco-friendly, and costeffective nanopolymers), phytosynthesis of Se-NPs using cinnamon extract (as a natural, biosafe, and bioactive method), and the innovative amalgamation of Cht-NPs with CIE/Se-NPs, evaluating their antimicrobial activities and potentiality for formulating bioactive ECs.

\section{Materials and Methods}

2.1. Chitosan Preparation. Cht was extracted from white prawn (Fenneropenaeus indicus) shell waste farmed in Kafrelsheikh University aquaculture farm, Egypt. Manually peeled shells were cleansed, dried, and pulverized. Shrimp shells were soaked in $2.0 \mathrm{~N} \mathrm{NaOH}$ and then in $2.0 \mathrm{~N} \mathrm{HCl}$ (at $1: 20 \mathrm{w} / \mathrm{v}$ ratios), for $4 \mathrm{~h}$ each at $25^{\circ} \mathrm{C}$ [30], followed each by extensive washing with deionized water (DIW) and drying at $45^{\circ} \mathrm{C}$ for $12 \mathrm{~h}$. Dry powdered Ct was immersed in $50 \% \mathrm{NaOH}$ solution ( $1 \mathrm{~g} \mathrm{Ct}$ powder $/ 25 \mathrm{~mL} \mathrm{NaOH})$ and put in an oil bath at $125^{\circ} \mathrm{C}$ for $130 \mathrm{~min}$ to obtain Cht [31]. The molecular Cht weight was assessed via GPC "gel permeation chromatography, Water Breeze, Waters, USA," whereas the DD "deacetylation degree" was calculated from Cht IR spectra using FTIR "Fourier transform infrared spectroscopy, FTIRV, 10.03.08; Perkin Elmer, Rodgau, Germany.”

2.2. Nano-Chitosan Preparation. Sodium tripolyphosphate "TPP; Sigma-Aldrich, St. Louis, MO, USA" was employed as a cross-linker for Cht-NP synthesis. Cht stock solution of $0.1 \%, \mathrm{w} / \mathrm{v}$ (in acetic acidified solution), and TPP solution of $0.5 \%, \mathrm{w} / \mathrm{v}$ (in DIW), were prepared. The solutions' $\mathrm{pH}$ values were adjusted to 5.2, after their paper filtration. While Cht solution was vigorously stirred, the solution of TPP was slowly dripped into it (at $0.3 \mathrm{~mL} / \mathrm{min}$ rate) using a syringe needle. The stirring of formed Cht-NPs opalescent suspension was sustained for additional $115 \mathrm{~min}$, and then the formed NP pellet was harvested via $10,500 \times \mathrm{g}$ speed centrifugation for $30 \mathrm{~min}$ and repeated washing with DIW [32].

2.3. Cinnamon Extract Preparation. Dry identified cinnamon (Cinnamomum zeylanicum) bark was obtained from the ARC "Agricultural Research Centre, Giza, Egypt." Pulverized and sieved bark powder (60 mesh) was dipped and rotated in 10 -folds (w/v) from $70 \%$ ethanol for $25 \mathrm{~h}$ at $165 \times \mathrm{g}$ and $25^{\circ} \mathrm{C}$. After filtration and discarding of bark residues, the resulting cinnamon extract (CIE) was vacuumevaporated at $44^{\circ} \mathrm{C}$ until dryness [33].

2.4. Phytosynthesis of Selenium Nanoparticles. The Se-NP phytosynthesis involved preparation of $10 \mathrm{mM}$ sodium selenite solution $\left(\mathrm{Na}_{2} \mathrm{SeO}_{3}\right.$; Sigma-Aldrich) and incorporation with equal volumes of $\mathrm{CIE}$ aqua solution to have overall CIE concentrations of $0.5 \%, 1.0 \%$, and $1.5 \%$ to preliminarily evaluate the CIE potentiality for Se-NP phytosynthesis. The biosynthesis conditions were the composited solutions stirring in dark at $210 \times \mathrm{g}$ for $6 \mathrm{~h}$ and $25^{\circ} \mathrm{C}$. The solution color changing to brownish-orange (due to Se-NP synthesis) was visually observed. The CIE-phytosynthesized Se-NPs (CIE/Se-NPs) were centrifuged at $12,500 \times \mathrm{g}$ for $28 \mathrm{~min}$ (Sigma 2-16 KL centrifuge; Sigma Lab. GmbH, Germany) at $15^{\circ} \mathrm{C}$, washed with DIW three times, recentrifuged, and subjected to analysis and characterization [34]. 
For nanocomposite formation from CIE/Se-NPs and Cht-NPs (mentioned thereafter as CIE/Se/Cht-NPs), prepared powders from Cht-NPs and CIE/Se-NPs were dissolved $(0.1 \%, \mathrm{w} / \mathrm{v})$ in $1 \%$ acetic solution and DIW, respectively, via vigorous stirring that was followed by sonication. NP solutions (equal volumes) were mixed and stirred for $90 \mathrm{~min}$, and then formed nanocomposites were precipitated via centrifugation, washing with DIW, recentrifugation, and then freeze-drying.

\subsection{Analysis of CIE/Se/Cht-NP Physiognomies}

2.5.1. FTIR Spectral Analysis. Infrared spectroscopic examinations of CIE, CIE/Se-NPs, and CIE/Se/Cht-NPs were conducted using the transmission mode of Perkin Elmer FTIR, Germany, after integrating samples with $1 \% \mathrm{KBr}$ "at wavenumbers ranging from $400-4000 \mathrm{~cm}^{-1}$."

2.5.2. Structural Analysis. The TEM imaging "transmission electron microscopy, Leo 0430; Leica, Cambridge, UK" was applied to assess the structural features "size, shape, morphology, and distribution" of phytosynthesized CIE/Se.

2.6. The Particles' Size (Ps) Distribution and the Zeta Potential. The Ps distribution and their zeta potential for synthesized Cht-NPs, CIE/Se-NPs, and CIE/Se/Cht-NPs were estimated via Zetasizer "Malvern Nano ZS instrument, Southborough, MA".

\subsection{Antibacterial Evaluation of Natural Products}

2.7.1. Bacteria Cultures. Standard strains of pathogenic food-borne bacterial "Escherichia coli ATCC-25922, Salmonella typhimurium ATCC-14028, Staphylococcus aureus ATCC-25923, and Listeria monocytogenes ATCC-19116" were employed for antibacterial screening. The microorganisms were maintained by subculturing on NA and NB "nutrient agar and nutrient broth, Difco Laboratories, Detroit, MI, USA” aerobically at $37^{\circ} \mathrm{C}$.

2.7.2. Qualitative Antimicrobial Assay of Nanocomposites. The ZOI "zones of growth inhibition," after treatment of each screened bacterium with nanocomposites, were appraised via disc diffusion test, as indicators of their antibacterial bioactivities. Sterile paper discs "Whatman no. 4, with $6 \mathrm{~mm}$ diameter" were impregnated with $25 \mu \mathrm{L}$ from $2 \%$ solutions of CIE, CIE/Se-NPs, or CIE/Se/Cht-NPs and sited onto a freshly inoculated NA plate with individual bacterial cultures. After upside plates' incubation for $18-24 \mathrm{~h}$ at $37^{\circ} \mathrm{C}$, the visualized ZOI diameters were precisely measured and their triplicate means \pm SDs (standard deviations) were calculated [5].

2.7.3. Quantitative Antimicrobial Assay of Nanocomposites. The MIC "minimal inhibitory concentration" of CIE, CIE/ Se-NPs, or CIE/Se/Cht-NPs was appraised using microdilution method [4]. The exposed bacteria $\left(2 \times 10^{7}\right.$ cell/ $\mathrm{mL}$ in $\mathrm{NB}$ medium) to gradual concentrations from each agent (ranged from 10 to $75 \mu \mathrm{g} / \mathrm{mL}$ in NB) were incubated for $16 \mathrm{~h}$ at $37^{\circ} \mathrm{C}$ and screened for turbidity. Subsequently, exposed wells were treated with TTC indicator solution "triphenyl tetrazolium chloride, Sigma-Aldrich" to confirm the bactericidal action, as viable cells transform TTC to violet-red color.

2.8. SEM "Scanning Electron Microscopy" Imaging of Nanocomposite-Treated Bacteria. SEM micrographs "JSM IT100; JEOL, Tokyo, Japan" were captured for determining the morphological and organizational alterations in S. typhimurium and E. coli cells after exposure to CIE/SeNPs to elucidate the potential action mode of NPs. Bacterial SEM imaging was implemented after cells' exposure to $25 \mu \mathrm{g} / \mathrm{mL}$ CIE/Se-NPs (in tryptic soy broth) for 0 (control), 5 , and $10 \mathrm{~h}$ and incubation at $37^{\circ} \mathrm{C}$. The treated cells were collected, washed with DIW, centrifuged at $4600 \times \mathrm{g}$ for $30 \mathrm{~min}$, and subjected to SEM preparation and imaging. The SEM micrographs' capturing was based on cell morphologies' modifications after nanocomposite exposure [35].

2.9. Coating Films Preparation and Evaluation. To prepare EC solutions, Cht-NP powder was gently dissolved (1.5\%, w/ v) in boiling DIW for $15 \mathrm{~min}$ with stirring $(140 \times \mathrm{g})$. The solution's temperature was reduced to $\sim 45^{\circ} \mathrm{C}$ while stirring, and then $1 \%(\mathrm{v} / \mathrm{v})$ acetic acid and $0.25 \mathrm{~mL}$ glycerol/g ChtNPs were added as plasticizer [36]. After additional $30 \mathrm{~min}$ of stirring, the solution temperature was kept at $\sim 37^{\circ} \mathrm{C}$ and then dispersed CIE/Se-NP composites in Tween 80 solution $(2 \% \mathrm{v} / \mathrm{v})$ were mixed with EC solutions to attain various CIE/ Se-NP concentrations in EC (i.e., 25, 50, and $75 \mu \mathrm{g} / \mathrm{mL}$ ). The achieved EC solution was poured into $15 \mathrm{~cm}$ plastic Petri dishes to create a film with $\sim 1.0-1.5 \mathrm{~mm}$ thickness and dried with warmed air at $43 \pm 2{ }^{\circ} \mathrm{C}$ in an incubator. The dried EC films were peeled and cut to $\sim 1 \mathrm{~cm}^{2}$ squares for use in the qualitative antibacterial assay, using EC squares instead of filter paper disks, as described previously.

2.10. Statistical Analysis. Triplicated experiments were performed; data were provided as means \pm SD. The SPSS package (SPSS version 11.5; SPSS, Chicago, IL, USA) was applied for statistical analysis.

\section{Results and Discussion}

3.1. Se-NP Phytosynthesis. The bioreduction of $\mathrm{Na}_{2} \mathrm{SeO}_{3}$ to Se-NPs was accomplished via CIE, as visually evinced by color changes of NP solution from whitish-yellow to brownish-orange (Figure 1). The optimal concentration from CIE to generate Se-NPs was $1.0 \%$, followed by $1.5 \%$ and $0.5 \%$, respectively, as noticed from the colors deepness of the phytosynthesized Se-NPs. The development of brownishorange color deepness was observed for all treatments with incubation prolongation, no additional color changings were observed after $4 \mathrm{~h}$ of incubation at $25^{\circ} \mathrm{C}$. 


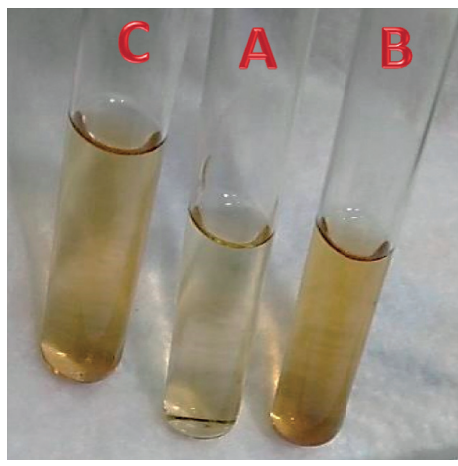

After $0.5 \mathrm{~h}$

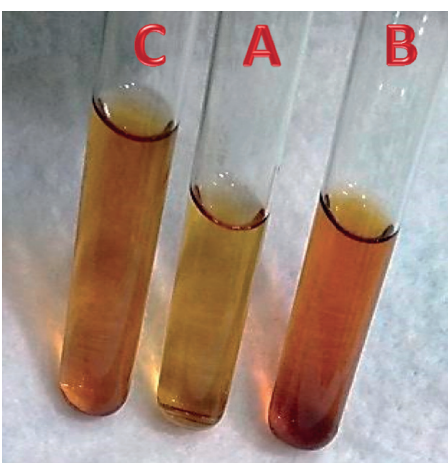

After $2 \mathrm{~h}$

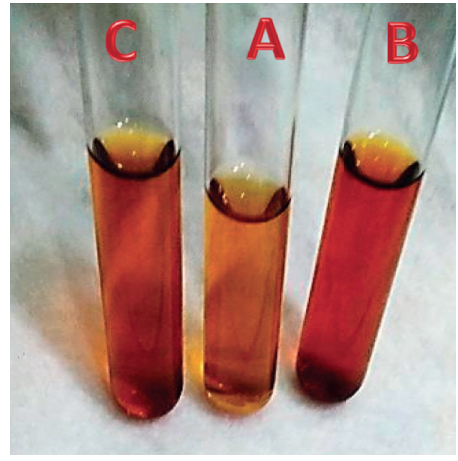

After $4 \mathrm{~h}$

Figure 1: Visual color change of biosynthesized Se-NPs using cinnamon extract after incubation of $10 \mathrm{mM}^{\circ} \mathrm{Na}_{2} \mathrm{SeO}_{3}$ with $0.5 \%$ (A), $1.0 \%$ (B), and $1.5 \%(\mathrm{C})$ from the extract for $0.5,2.0$, and $4.0 \mathrm{~h}$ at $25^{\circ} \mathrm{C}$.

The illustrated Se-NP phytosynthesis protocol is ecofriendly, simple, and cheap; the resultant NPs are assumed to be innocent, nontoxic, and highly stable $[19,37]$. The color changes of Se-NPs, during synthesis, and their correlation with Ps were stated [38].

3.2. FTIR Analysis. The biochemical groups, bonds and their interactions in the generated molecules are appointed through their FTIR spectra (Figure 2).

The pure Cht-NP spectrum (Figure 2, black) represented the FTIR spectra of pure powder, where typical bands could be observed at wavenumbers $\sim 3456.7 \mathrm{~cm}^{-1}$ (O-H stretch), $2883.4 \mathrm{~cm}^{-1}$ (C-H stretch), $1621.2 \mathrm{~cm}^{-1}$ (N-H bend), $1378.3 \mathrm{~cm}^{-1}$ (bridge $\mathrm{O}$ stretch), and $1134.8 \mathrm{~cm}^{-1}$ (C-O-C bonds). The bands located at wavenumber $\sim 1062.5 \mathrm{~cm}^{-1}$ were assigned to the $\mathrm{C}-\mathrm{O}$ stretch of glycosidic bonds $[39,40]$.

The Cht absorption band was similar to that of $\mathrm{Ct}$. The differences occurred after the deacetylation step, wherein there were changes in the absorption spectrum at $1688.7 \mathrm{~cm}^{-1}$ from the $C=O$ stretch [31].

The characteristic fingerprints of CIE were mostly present between $1650-600 \mathrm{~cm}^{-1}$ range (Figure 2, violet). The peak at $\sim 1604.3 \mathrm{~cm}^{-1}$ corresponded to the stretching vibration of aldehyde carbonyl $C=O$. The peak at $1445.7 \mathrm{~cm}^{-1}$ was typical for alcohol $\mathrm{C}-\mathrm{OH}$. The cinnamon peaks at $\sim 987.4$ and $1071.3 \mathrm{~cm}^{-1}$ were attributed to the stretching vibrations of $\mathrm{C}-\mathrm{O}$ and $\mathrm{C}-\mathrm{OH}$ deformation. The peak at $1281.9 \mathrm{~cm}^{-1}$ was attributed to $\mathrm{C}-\mathrm{H}_{2}$ alkanes that face the swing and the aromatic ring $\mathrm{C}-\mathrm{H}$ for in-plane bending absorption [41, 42].

For CIE/Se-NPs, the possible biomolecules responsible for the reduction of $\mathrm{Se}^{+}$ions and capping of bioreduced SeNPs phytosynthesized using CIE were identified [43]. FTIR spectra were used to identify the capping reagent and stability of the metal NPs present in cinnamon. The observed peak denoted the $\mathrm{O}-\mathrm{H}$ stretching group of phenols and alcohols at $3418.4 \mathrm{~cm}^{-1}$; it also denoted the carbonyl group at $1629.7 \mathrm{~cm}^{-1}$ [44].

The broad absorption band at $\sim 3410 \mathrm{~cm}^{-1}$ appeared due to $\mathrm{O}-\mathrm{H}$ stretching. The shifted band from $1604.3 \mathrm{~cm}^{-1}$ (in CIE) to $1629.7 \mathrm{~cm}^{-1}$ (in CIE/Se-NP spectrum) indicated the involvement of the $C=O$ bond in cinnamon aldehyde in Se-

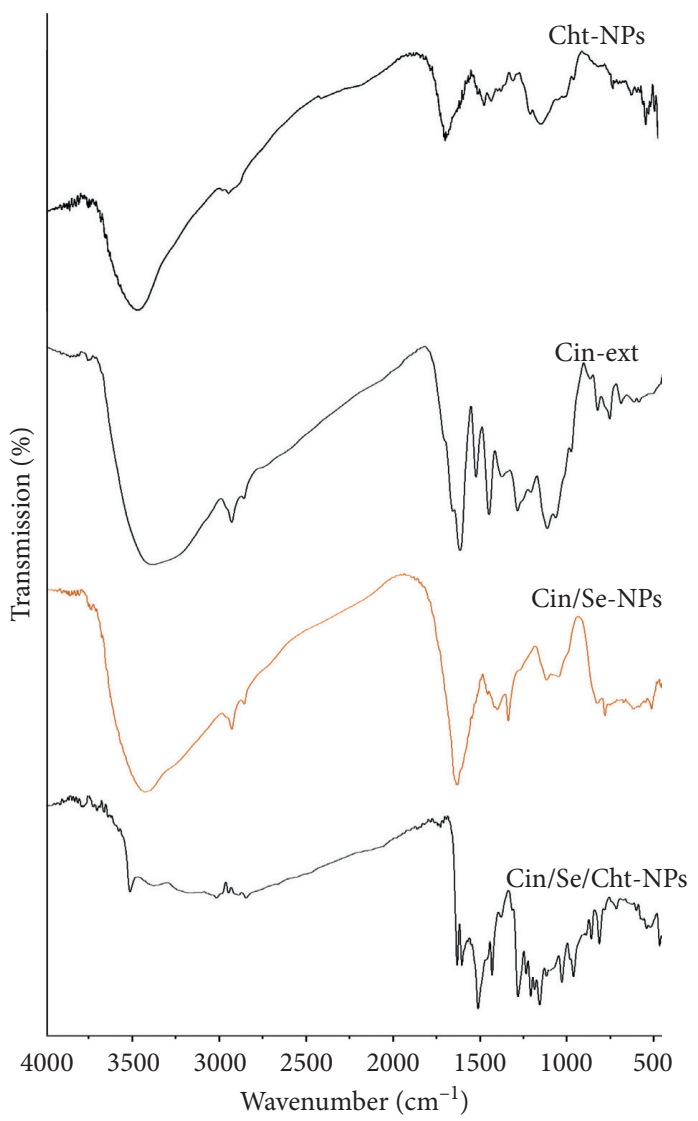

FIGURE 2: FTIR spectra of plain chitosan nanoparticles (Cht-NPs), cinnamon bark extract (Cin-ext), synthesized selenium nanoparticles with cinnamon extract (Cin/Se-NPs), and their nanocomposites with nano-chitosan (Cin/Se/Cht-NPs).

NP synthesis. The band at $1336.2 \mathrm{~cm}^{-1}$ corresponded to nitro compounds. This band was broader than the normal cases of aldehyde compounds due to the influence of conjugation and aromatic ring. The band at $1407.3 \mathrm{~cm}^{-1}$ was due to the aromatic $C=C$ bending, and the band at $1087.6 \mathrm{~cm}^{-1}$ was due to $\mathrm{C}-\mathrm{O}$ stretching $[45,46]$.

The FTIR spectrum of the CIE/Se/Cht nanocomposite had the main distinctive peaks from each combined agent, 
indicating the physiochemical reactions between these components, as evidenced by the shifts and differences in the transmission intensities of the characteristic bands.

3.3. Ps Distribution and NP Charges. The Ps distribution and their zeta potential for the synthesized Cht-NPs, CIE/SeNPs, and CIE/Se/Cht-NPs are appraised in Table 1. The successfulness of CIE to generate Se-NPs with minute Ps range and mean diameter was proved. The phytosynthesized Se-NPs had negative Z-potential $(-28.6 \mathrm{mV})$, whereas the Cht-NPs (with mean Ps of $42.1 \mathrm{~nm}$ ) had strong positive surface charges $(+39.4 \mathrm{mV})$. The nanocomposites of both NP types (CIE/Se/Cht-NPs) had slightly larger Ps range and mean diameters, which indicates their conjugation and integrations. The recorded Z-potential for investigated NPs indicated their high stability in solutions. These findings matched former stated results that suggested the formation of Cht and Se-NP nanocomposites with elevated stabilities and minute Ps $[29,47]$.

3.4. TEM Analysis of Se-NPs with CIE. The Ps investigation of CIE/Se-NPs via TEM micrographs showed that the size of NP ranged from 6.8 to $58.2 \mathrm{~nm}$, with mean Ps diameters of $\sim 23.2 \mathrm{~nm}$.

The TEM images of phytosynthesized CIE/Se-NPs verified the homogenous NP distribution and their stabilization with CIE during phytosynthesis. Se-NPs were spherical in shapes with nearly no aggregation (Figure 3). Little CIE particles were appeared in combination with Se-NPs in the CIE/Se-NP matrix, as was formerly indicated using other plant extracts [48]. Previous studies investigated plant derivatives employment for achieving different Se-NP particle shapes and sizes based on the employed phytochemical reducing agents. For example, fenugreek seeds extraction generated Se-NPs with smoothly oval shaped and Ps of 50-150 nm [49], dried raisin extract with 3-18 nm Se nanoballs [50], Bougainvillea spectabilis flower with spherical shape of Se-NPs with Ps ranges between 18 and $35 \mathrm{~nm}$ [51], and spherical NPs with Ps $102-170 \mathrm{~nm}$ were achieved by microbial phytosynthesis [52]. The biomolecules and several organic compounds found in the plant extract (e.g., $\mathrm{CIE}$ ) could lead to NP reduction and stabilization and stopping their aggregation [34].

3.5. Synthesis of Chitosan Nanoparticles. Cht-NP synthesis was efficaciously attained using the TPP gelation method, as evidenced by NP SEM imaging (Figure 4).

The Cht-NPs' appearance was semispherical and welldistributed, with PS of $\sim 17.3-73.9 \mathrm{~nm}$ and a mean diameter of $\sim 42.1 \mathrm{~nm}$ (Table 1). TPP cross-linkages were formerly verified as effective protocols for Cht-NP synthesis using the ionic-gelation interaction $[32,39]$. The current synthesized Cht-NPs with this protocol had extraordinary properties, compared to bulk Cht, for applications as plain antibacterial agents, nanocarriers for bioactive constituents, and bases for functional ECs $[10,25]$.
3.6. Antibacterial Activity of Cinnamon Phytosynthesized SeNPs. The antibacterial actions of CIE, CIE/Se-NP, and CIE/ Se/Cht-NP composites were experimentally quantified with different assessments against four food-borne bacteria (Table 2). The CIE/Se/Cht-NP composite had the highest effectiveness and exhibited superior antibacterial activity. The qualitative ZOI and quantitative MIC assays revealed significant antibacterial action of the prepared antibacterial agents, as follows: $\mathrm{CIE}<\mathrm{CIE} / \mathrm{Se}-\mathrm{NPs}<\mathrm{CIE} / \mathrm{Se} / \mathrm{Cht}-\mathrm{NPs}$. S. typhimurium was significantly higher sensitive to CIE than the other species. In contrast, the most CIE/Se/Cht-NP resistant bacterium was $L$. monocytogenes. Generally, the sensitivity of tested bacteria to examined agents was: Gramnegative $<$ Gram-positive

(S. typhimurium $<$ E. coli $<$ S. aureus $<$ L. monocytogenes).

The CIE antimicrobial potentialities (including antibacterial, antifungal, and antiviral activities) were stated in many reports and attributed to its precious contents from active phytochemicals, e.g., cinnamaldehyde, eugenol, B-caryophyllene, ethyl cinnamate, and terpenes $[24,41,53,54]$. Conjugation of CIE with its green synthesized metals' NPs was validated to reinforce their combined antimicrobial performance, mostly because the synergistic actions of NPs and CIE phytochemicals can attack the microbial cells via diverse mechanisms, which are assumingly very hard to gain resistance toward them all $[43,45,55-57]$.

3.7. SEM Analysis of Treated Bacteria. The effect of CIE/SeNP exposure on the cellular morphology and cell wall deformation of bacterial strains (S. typhimurium and E. coli) are shown in Figure 5. The selection of screened strains was based on their higher sensitivity to nanocomposites; therefore, they were expected to provide more evidences for the antimicrobial action. The bacterial cells had healthy appearance with normal, smooth, and contracted shapes at the beginning of exposure time (control; Figure 5, 0h)). Apparent morphological changes in the bacterial cell were occurred after $5 \mathrm{~h}$ exposure to CIE/SeNPs; bacterial walls converted to puffy walls, and many NPs attached the cell membranes, disrupt them and enter the cells at this stage. The bacterial cell viability decreased and many cells were lysed after exposure to CIE/Se-NPs (Figure 5, $5 \mathrm{~h}$ ).

With prolonged CIE/Se-NP exposure to $10 \mathrm{~h}$, the compromised NPs with bacterial cells became more apparent with higher numbers. The bacterial cells were mostly lysed at this time; their released interior components apparently attached with CIE/Se-NPs. The CIE antibacterial activity was supposed to involve complex mechanisms, including suppression of nucleic acid metabolism and activity, restraint of cell wall/membrane synthesis, and deactivation of intracellular components and proteins [58, 59]. Furthermore, Se polymeric coatings were proposed as innovative antibacterial agents via the reduction of biological functions of microbes [60]. The shape and size of phytosynthesized CIE/Se-NPs augmented their antibacterial action. It was recently proposed that spherical and 
Table 1: The Ps distribution and their zeta potential for synthesized Cht-NPs, CIE/Se-NPs, and CIE/Se/Cht-NPs.

\begin{tabular}{lccc}
\hline NPs & Size range $(\mathrm{nm})$ & Mean diameter $(\mathrm{nm})$ & Zeta potential $(\mathrm{mV})$ \\
\hline CIE/Se-NPs & $6.8-58.2$ & 23.2 & -28.6 \\
Cht-NPs & $17.3-73.9$ & 42.1 & +39.4 \\
CIE/Se/Cht-NPs & $19.6-84.1$ & 51.9 & +32.3 \\
\hline
\end{tabular}

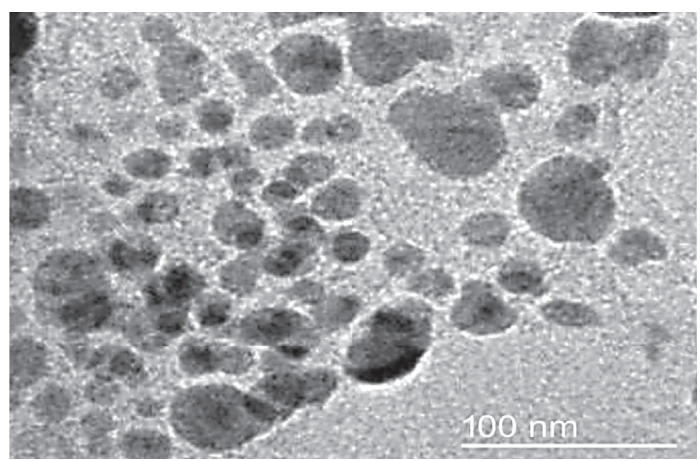

FIgURE 3: TEM micrograph of phytosynthesized Se-NPs with cinnamon bark extract.

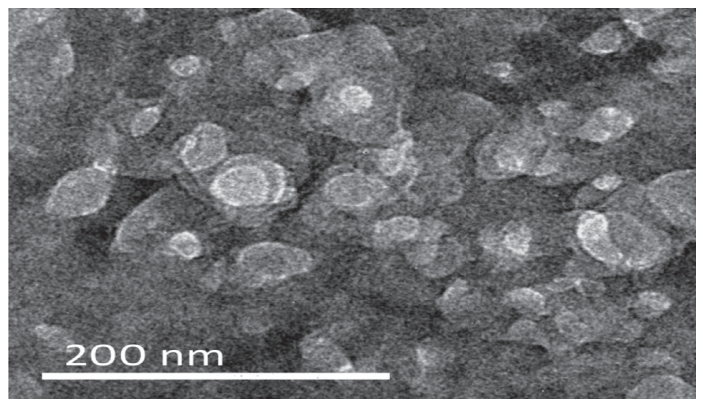

FIGURE 4: Scanning micrographs of chitosan nanoparticles synthesized using ionic-gelation method.

TAвle 2: Antimicrobial capacities of phycosynthesized Se nanoparticles with cinnamon extract against food-borne bacteria.

\begin{tabular}{|c|c|c|c|c|c|c|c|c|}
\hline \multirow{3}{*}{ Examined agents } & \multicolumn{8}{|c|}{ Antibacterial activity** } \\
\hline & \multicolumn{2}{|c|}{ E. coli } & \multicolumn{2}{|c|}{ Salmonella typhimurium } & \multicolumn{2}{|c|}{ Staphylococcus aureus } & \multicolumn{2}{|c|}{ Listeria monocytogenes } \\
\hline & $\mathrm{ZOI}(\mathrm{mm})^{*}$ & $\operatorname{MIC}(\mu \mathrm{g} / \mathrm{ml})$ & $\mathrm{ZOI}(\mathrm{mm})$ & $\operatorname{MIC}(\mu \mathrm{g} / \mathrm{ml})$ & $\mathrm{ZOI}(\mathrm{mm})$ & $\mathrm{MIC}(\mu \mathrm{g} / \mathrm{ml})$ & $\mathrm{ZOI}(\mathrm{mm})$ & $\operatorname{MIC}(\mu \mathrm{g} / \mathrm{ml})$ \\
\hline Cinnamon Ext. & $12.1 \pm 0.7^{\mathrm{a}}$ & 40.0 & $12.8 \pm 0.8^{\mathrm{a}}$ & 37.5 & $9.9 \pm 0.7^{\mathrm{a}}$ & 47.5 & $8.7 \pm 0.5^{\mathrm{a}}$ & 50.0 \\
\hline CIE/Se-NPs & $15.3 \pm 1.2^{\mathrm{b}}$ & 32.5 & $16.2 \pm 1.2^{\mathrm{b}}$ & 30.0 & $12.7 \pm 1.1^{\mathrm{b}}$ & 35.0 & $11.7 \pm 1.0^{\mathrm{b}}$ & 37.5 \\
\hline $\mathrm{CIE} / \mathrm{Se} / \mathrm{Cht}-\mathrm{NPs}$ & $18.4 \pm 1.4^{\mathrm{c}}$ & 22.5 & $20.9 \pm 1.6^{\mathrm{c}}$ & 20.0 & $17.8 \pm 1.2^{\mathrm{c}}$ & 27.5 & $17.2 \pm 1.1^{\mathrm{c}}$ & 27.5 \\
\hline
\end{tabular}

${ }^{*}$ Inhibition zones impart triplicates' diameter means \pm SD, assay discs (diameter $6 \mathrm{~mm}$ ) carrying $50 \mu \mathrm{g}$ from cinnamon extract (CIE), phytosynthesized SeNPs with cinnamon extract (CIE/Se-NPs) or their blend with nano-chitosan (CIE/Se/Cht-NPs). ${ }^{* *}$ "Dissimilar superscript letters within the same column indicate significant difference at $p<0.05$."

smaller-sized Se-NPs could easily access the bacterial cell wall/membrane and hinder their biological activities [34].

Se-NPs exhibited more inhibitory actions against Gram + ve bacterial species in the current and previous investigations (including Proteus sp. and Serratia sp.), as explained by the lesser surface charges of NPs that effectively enabled them to bind to the bacterial cell membrane [37]. The antibacterial action of Se ions also depended on their absorption and accumulation onto microbial cells, leading to cytoplasm membrane shrinkage and cell bioactivity inhibition [35].

The definite mechanisms of Se-NPs as antimicrobial substances are still ambiguous, but former studies claimed that generating ROS "reactive oxygen species" and free radicals are major causes of bacterial cells' devastation by Se organic compounds $[61,62]$. The metallic NP antimicrobial 


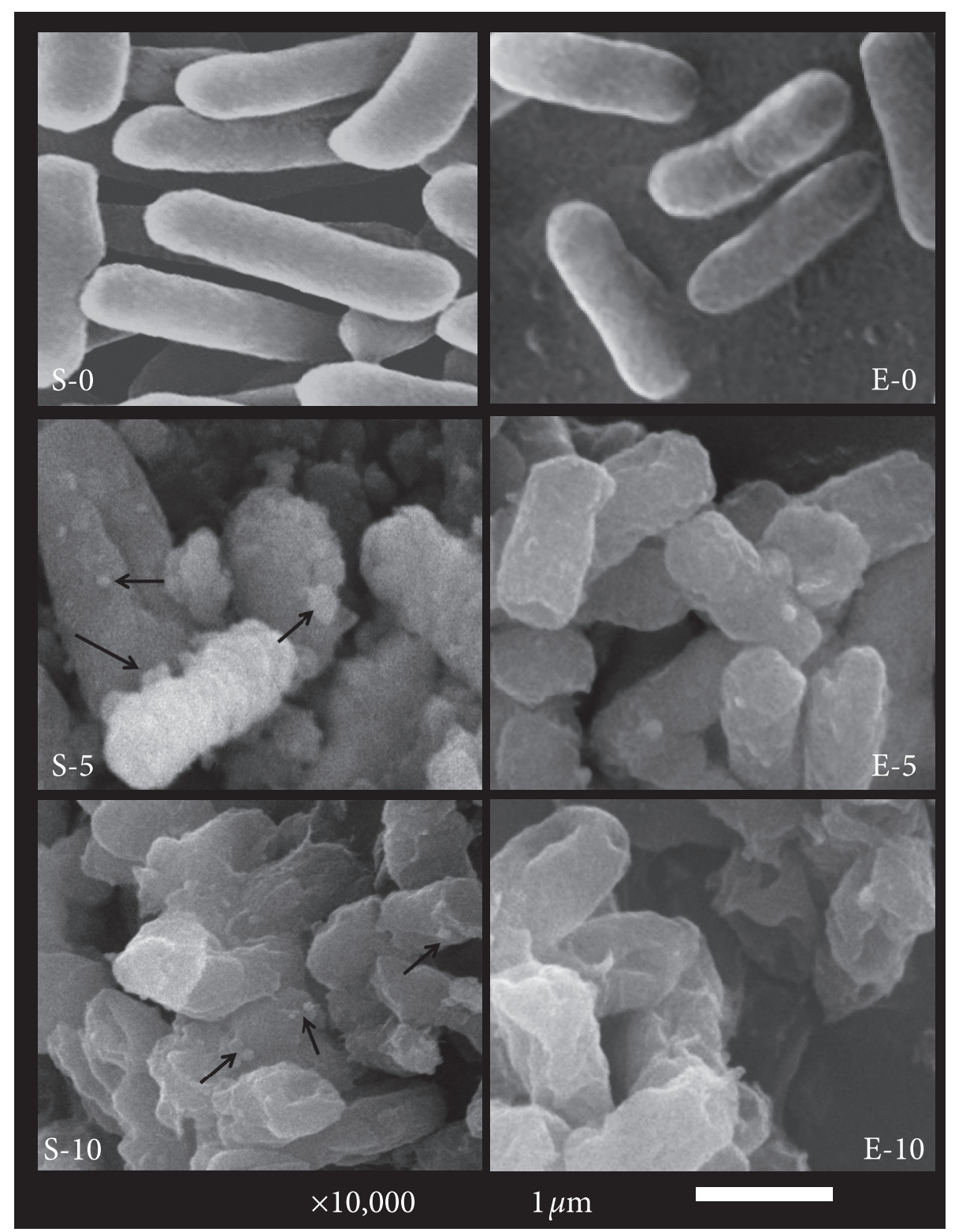

FIgURE 5: SEM micrographs of exposed Salmonella typhimurium (S) and E. coli (E) to phytosynthesized Se-NPs with cinnamon bark extract after 0,5 , and $10 \mathrm{~h}$ of treatment. Arrows indicate the some attached Se-NPs to compromised bacterial cells.

activities were attributed to their interactions with intracellular vital components (DNA, ribosomes, and RNA) to alter and deactivate their bioactive processes [63]. From former investigations, SEM and TEM imaging of exposed bacteria, S. aureus and E. coli, to Se-NPs indicated cells' wall shrinking, deformation, and damage [64], suggesting that Se-NPs can destroy bacteria via penetrating their cell membrane with increased ROS production.

3.8. Antimicrobial Capacities of Synthesized Edible Coating. The antibacterial capacities of Cht-NP (1.5\%), Cht$\mathrm{NP}+\mathrm{CIE} / \mathrm{Se}-\mathrm{NP}(25 \mu \mathrm{g} / \mathrm{mL})$, Cht-NP + CIE/Se-NP $(50 \mu \mathrm{g} /$ $\mathrm{mL})$, and Cht-NP + CIE/Se-NP $(75 \mu \mathrm{g} / \mathrm{mL})$ ECs were validated against the four challenged food-borne pathogens (Table 3). The Cht-NP+CIE/Se-NP $(75 \mu \mathrm{g} / \mathrm{mL})$ EC was significantly the most forceful. Qualitative ZOI assay exhibited remarkable antibacterial actions of the prepared ECs, which augmented with CIE/Se-NP concentrations in Cht-NP- based ECs.

The composed ECs and films from Cht and Cht-NPs, after conjugation with bioactive phytochemicals, had evidenced extra activities and applicability for usage in foodstuff protection and preservation $[10,12,36,65]$; the antioxidant, antimicrobial, and polymeric nature of ChtNPs could increase the actions of conjugated materials to prevent food spoilage factors. From the documented advantageous attributes of the components of produced EC nanocomposites, i.e., Cht-NPs (antioxidant, surface barring, and antimicrobial activities), CIE (antimicrobial and antioxidant activities), and Se-NPs (powerful microbicidal action); these nanocomposited ECs are supposed to have 
TABle 3: Antimicrobial capacities of formulated edible coating from chitosan nanoparticles (Cht-NPs) and phycosynthesized Se nanoparticles with cinnamon extract (CIE/Se-NPs) against food-borne bacteria.

\begin{tabular}{lcccc}
\hline \multirow{2}{*}{ Edible coating } & \multicolumn{3}{c}{ Antibacterial activity (IZ: mm)* } \\
& E. coli & Salmonella typhimurium & Staphylococcus aureus & Listeria monocytogenes \\
\hline Cht-NPs $(1.5 \%)$ & $5.5 \pm 0.5$ & $6.1 \pm 0.4$ & $5.1 \pm 0.3$ & $4.6 \pm 0.4$ \\
Cht-NPs + CIE/Se-NPs $(25 \mu \mathrm{g} / \mathrm{ml})$ & $8.6 \pm 0.7$ & $10.1 \pm 0.9$ & $7.5 \pm 0.6$ & $7.2 \pm 0.7$ \\
Cht-NPs + CIE/Se-NPs $(50 \mu \mathrm{g} / \mathrm{ml})$ & $10.8 \pm 0.9$ & $12.2 \pm 1.2$ & $8.9 \pm 0.8$ & $8.4 \pm 1.0$ \\
Cht-NPs + CIE/Se-NPs $(75 \mu \mathrm{g} / \mathrm{ml})$ & $13.2 \pm 1.2$ & $14.8 \pm 1.4$ & $10.9 \pm \mathrm{I} 0.9$ & $10.1 \pm 1.1$ \\
\hline
\end{tabular}

*Inhibition zones impart triplicates' diameter means \pm SD, Inhibition zones impart triplicates' diameter means \pm SD, without coating films diameter $p|<| 0.05$.

elevated capability for protecting foodstuff from external spoilage factors (e.g., oxygen and free radicals attack and cross contamination) besides the internal factors (microbial load, lipid oxidation, and enzymatic actions), using these biosafe and natural components [7, 12, 37, 66].

\section{Conclusion}

The synthesis of Cht-NPs and green synthesized Se-NPs with CIE was successfully achieved. The phytosynthesized Se-NP had mean diameter of $23.2 \mathrm{~nm}$, spherical shape, and high stability. The CIE/Se/Cht-NP composite exhibited potent antibacterial action against different food-borne bacterial pathogens. The bactericidal action was confirmed by imaging and antimicrobial assays, and the efficiency of phytosynthesized NPs was validated. The CIE/Se/Cht-NP bioactive edible coatings were additionally formulated and their capability to prohibit food-borne bacterial growth was evidenced. The based coating on CIE/Se/Cht-NP nanocomposites could be outstandingly recommended for the prospective applications in foodstuff preservation.

\section{Data Availability}

The datasets generated during and/or analyzed during the current study are available from the corresponding author on reasonable request.

\section{Conflicts of Interest}

The authors declare that they have no conflicts of interest.

\section{References}

[1] H. No, Y. P. Na, S. H. Lee, and S. P. Meyers, “Antibacterial activity of chitosans and chitosan oligomers with different molecular weights," International Journal of Food Microbiology, vol. 74, no. 1-2, pp. 65-72, 2002.

[2] S. Kou, L. M. Peters, and M. R. Mucalo, "Chitosan: a review of sources and preparation methods," International Journal of Biological Macromolecules, vol. 169, pp. 85-94, 2021.

[3] M. Kong, X. G. Chen, K. Xing, and H. J. Park, “Antimicrobial properties of chitosan and mode of action: a state of the art review," International Journal of Food Microbiology, vol. 144, no. 1, pp. 51-63, 2010.

[4] A. A. Tayel, W. F. El-Tras, S. Moussa et al., "Antibacterial action of zinc oxide nanoparticles against foodborne pathogens," Journal of Food Safety, vol. 31, no. 2, pp. 211-218, 2011.
[5] A. A. Tayel, S. Moussa, K. Opwis, D. Knittel, E. Schollmeyer, and A. Nickisch-Hartfiel, "Inhibition of microbial pathogens by fungal chitosan," International Journal of Biological Macromolecules, vol. 47, no. 1, pp. 10-14, 2010.

[6] S. Preethi, K. Abarna, M. Nithyasri et al., "Synthesis and characterization of chitosan/zinc oxide nanocomposite for antibacterial activity onto cotton fabrics and dye degradation applications," International Journal of Biological Macromolecules, vol. 164, pp. 2779-2787, 2020.

[7] A. A. Tayel, A. F. Elzahy, S. H. Moussa, M. S. Al-Saggaf, and A. M. Diab, "Biopreservation of shrimps using composed edible coatings from chitosan nanoparticles and cloves extract," Journal of Food Quality, vol. 2020, Article ID 8878452, 10 pages, 2020.

[8] A. A. Tayel, M. M. Gharieb, H. R. Zaki, and N. M. Elguindy, "Bio-clarification of water from heavy metals and microbial effluence using fungal chitosan," International Journal of Biological Macromolecules, vol. 83, pp. 277-281, 2016.

[9] A. I. Alalawy, H. A. El Rabey, F. M. Almutairi et al., "Effectual anticancer potentiality of loaded bee venom onto fungal chitosan nanoparticles," International Journal of Polymer Science, vol. 2020, Article ID 2785304, 9 pages, 2020.

[10] M. A. Alotaibi, A. A. Tayel, N. S. Zidan, and H. A. El Rabey, "Bioactive coatings from nano-biopolymers/plant extract composites for complete protection from mycotoxigenic fungi in dates," Journal of the Science of Food and Agriculture, vol. 99, no. 9, pp. 4338-4343, 2019.

[11] D. Bharathi, R. Ranjithkumar, B. Chandarshekar, and V. Bhuvaneshwari, "Preparation of chitosan coated zinc oxide nanocomposite for enhanced antibacterial and photocatalytic activity: as a bionanocomposite," International Journal of Biological Macromolecules, vol. 129, pp. 989-996, 2019a.

[12] D. R. Perinelli, L. Fagioli, R. Campana et al., "Chitosan-based nanosystems and their exploited antimicrobial activity," European Journal of Pharmaceutical Sciences, vol. 117, pp. 8-20, 2018.

[13] J. Zhang, S. Y. Zhang, J. Xu, and H. Y. Chen, "A new method for the synthesis of selenium nanoparticles and the application to construction of $\mathrm{H}_{2} \mathrm{O}_{2}$ biosensor," Chinese Chemical Letters, vol. 15, pp. 1345-1348, 2004.

[14] B. Hosnedlova, M. Kepinska, S. Skalickova et al., "A summary of new findings on the biological effects of selenium in selected animal species-A critical review," International Journal of Molecular Sciences, vol. 18, no. 10, p. 2209, 2017.

[15] X. Gao, J. Zhang, and L. Zhang, "Hollow sphere selenium nanoparticles: their in-vitro anti hydroxyl radical effect," Advanced Materials, vol. 14, no. 4, p. 290, 2002.

[16] X. Y. Gao, J. S. Zhang, L. D. Zhang, and M. X. Zhu, "Nano-Se has a 7-fold lower acute toxicity than sodium selenite in mice," China Public Health, vol. 16, p. 421, 2000.

[17] I. M. Helander, E.-L. Nurmiaho-Lassila, R. Ahvenainen, J. Rhoades, and S. Roller, "Chitosan disrupts the barrier 
properties of the outer membrane of gram-negative bacteria," International Journal of Food Microbiology, vol. 71, no. 2-3, pp. 235-244, 2001.

[18] A. Kumar and K. S. Prasad, "Role of nano-selenium in health and environment," Journal of Biotechnology, vol. 325, pp. 152-163, 2021.

[19] J.-S. Zhang, X.-Y. Gao, L.-D. Zhang, and Y.-P. Bao, "Biological effects of a nano red elemental selenium," Biofactors, vol. 15, no. 1, pp. 27-38, 2001.

[20] O. P. Snyder, Antimicrobial Effects of Spices and Herbs, Hospitality Institute of Technology and Management, St. Paul, Minnaesota, 1997, http://www.hitm.com/Documents/Spices.html.

[21] A. Govaris, N. Solomakos, A. Pexara, and P. S. Chatzopoulou, "The antimicrobial effect of oregano essential oil, nisin and their combination against Salmonella Enteritidis in minced sheep meat during refrigerated storage," International Journal of Food Microbiology, vol. 137, no. 2-3, pp. 175-180, 2010.

[22] P. Mayachiew and S. Devahastin, "Antimicrobial and antioxidant activities of Indian gooseberry and galangal extracts," LWT-Food Science and Technology, vol. 41, no. 7, pp. 11531159, 2008.

[23] A. Sangal, "Role of cinnamon as beneficial antidiabetic food adjunct: a review," Advances in Applied Science Research, vol. 2, no. 4, pp. 440-450, 2011.

[24] M. Vangalapati, N. Sree Satya, D. Surya Prakash, and S. Avanigadda, "A review on pharmacological activities and clinical effects of cinnamon species," Research Journal of Pharmaceutical, Biological and Chemical Sciences, vol. 3, no. 1, pp. 653-663, 2012.

[25] S. Guilbert, "Edible films and coatings and biodegradable packaging," Bulletin of the International Dairy Federation, vol. 346, pp. 10-16, 2000.

[26] S. Wu, "Effect of chitosan-based edible coating on preservation of white shrimp during partially frozen storage," International Journal of Biological Macromolecules, vol. 65, pp. 325-328, 2014.

[27] D. Bharathi, R. Ranjithkumar, B. Chandarshekar, and V. Bhuvaneshwari, "Bio-inspired synthesis of chitosan/copper oxide nanocomposite using rutin and their anti-proliferative activity in human lung cancer cells," International Journal of Biological Macromolecules, vol. 141, pp. 476-483, $2019 \mathrm{~b}$.

[28] C. N. Nandana, M. Christeena, and D. Bharathi, "Synthesis and characterization of chitosan/silver nanocomposite using rutin for antibacterial, antioxidant and photocatalytic applications," Journal of Cluster Science, vol. 82, 2021.

[29] L. Rao, Y. Ma, M. Zhuang, T. Luo, Y. Wang, and A. Hong, "Chitosan-decorated selenium nanoparticles as protein carriers to improve the in vivo half-life of the peptide therapeutic BAY 55-9837 for type 2 diabetes mellitus," International Journal of Nanomedicine, vol. 9, p. 4819, 2014.

[30] K. L. B. Chang, G. Tsai, J. Lee, and W.-R. Fu, "Heterogeneous $\mathrm{N}$-deacetylation of chitin in alkaline solution," Carbohydrate Research, vol. 303, no. 3, pp. 327-332, 1997.

[31] R. F. Weska, J. M. Moura, L. M. Batista, J. Rizzi, and L. A. A. Pinto, "Optimization of deacetylation in the production of chitosan from shrimp wastes: use of response surface methodology," Journal of Food Engineering, vol. 80, no. 3, pp. 749-753, 2007.

[32] P. Calvo, C. Remu-Pez, J. L. Vila-Jato, and M. J. Alonso, "Novel hydrophilic chitosan-polyethylene oxide nanoparticles as protein carriers," Journal of Applied Polymer Science, vol. 63, no. 1, pp. 125-132, 1997.

[33] A. A. Tayel, W. F. El-Tras, S. H. Moussa, and S. M. El-Sabbagh, "Surface decontamination and quality enhancement in meat steaks using plant extracts as natural biopreservatives," Foodborne Pathogens and Disease, vol. 9, no. 8, pp. 755-761, 2012.

[34] S. Menon, S. D. K.S., H. Agarwal, and V. K. Shanmugam, "Efficacy of biogenic selenium nanoparticles from an extract of ginger towards evaluation on anti-microbial and anti-oxidant activities," Colloid and Interface Science Communications, vol. 29, pp. 1-8, 2019.

[35] M. Mohammadlou, H. Jafarizadeh-Malmiri, and H. Maghsoudi, "Hydrothermal green synthesis of silver nanoparticles using Pelargonium/Geranium leaf extract and evaluation of their antifungal activity," Green Processing and Synthesis, vol. 6, no. 1, pp. 31-42, 2017.

[36] C. Caner and O. Cansiz, "Effectiveness of chitosan-based coating in improving shelf-life of eggs," Journal of the Science of Food and Agriculture, vol. 87, no. 2, pp. 227-232, 2007.

[37] E. Zonaro, S. Lampis, R. J. Turner, S. J. S. Qazi, and G. Vallini, "Biogenic selenium and tellurium nanoparticles synthesized by environmental microbial isolates efficaciously inhibit bacterial planktonic cultures and biofilms," Frontiers in Microbiology, vol. 6, pp. 1-11, 2015.

[38] Z. H. Lin and C. C. Wang, "Evidence on the size-dependent absorption spectral evolution of selenium nanoparticles," Materials Chemistry and Physics, vol. 92, no. 2-3, pp. 591-594, 2005.

[39] T. K. Glaser, O. Plohl, A. Vesel et al., "Functionalization of polyethylene (PE) and polypropylene (PP) material using chitosan nanoparticles with incorporated resveratrol as potential active packaging," Materials, vol. 12, no. 13, p. 2118, 2019.

[40] A. A. Tayel, S. I. A. Ibrahim, M. A. Al-Saman, and S. H. Moussa, "Production of fungal chitosan from date wastes and its application as a biopreservative for minced meat," International Journal of Biological Macromolecules, vol. 69, pp. 471-475, 2014.

[41] Y.-q. Li, D.-x. Kong, and H. Wu, "Analysis and evaluation of essential oil components of cinnamon barks using GC-MS and FTIR spectroscopy," Industrial Crops and Products, vol. 41, pp. 269-278, 2013.

[42] S. Potrc, L. F. Zemljic, M. Sterniša, S. S. Možina, and O. Plohl, "Development of biodegradable whey-based laminate functionalised by chitosan-natural extract formulations," International Journal of Molecular Sciences, vol. 21, p. 3668, 2020.

[43] J. Premkumar, T. Sudhakar, A. Dhakal, J. B. Shrestha, S. Krishnakumar, and P. Balashanmugam, "Synthesis of silver nanoparticles (AgNPs) from cinnamon against bacterial pathogens," Biocatalysis and Agricultural Biotechnology, vol. 15, pp. 311-316, 2018.

[44] V. Kulkarni and P. Tanpure, "Biosynthesis of silver nanoparticles by using the cinnamon (dalchini) extract," Current Pharma Research, vol. 9, no. 2, pp. 2716-2720, 2019.

[45] D. Goyal, A. Saini, G. S. S. Saini, and R. Kumar, "Green synthesis of anisotropic gold nanoparticles using cinnamon with superior antibacterial activity," Materials Research Express, vol. 6, no. 7, Article ID 075043, 2019.

[46] V. V. Makarov, A. J. Love, O. V. Sinitsyna et al., "'Green" nanotechnologies: synthesis of metal nanoparticles using plants," Acta Naturae, vol. 6, no. 1, pp. 35-44, 2014.

[47] W. Chen, L. Yue, Q. Jiang, X. Liu, and W. Xia, "Synthesis of varisized chitosan-selenium nanocomposites through heating treatment and evaluation of their antioxidant properties," International Journal of Biological Macromolecules, vol. 114, pp. 751-758, 2018. 
[48] M. S. Al-Saggaf, A. A. Tayel, M. O. I. Ghobashy, M. A. Alotaibi, M. A. Alghuthaymi, and S. H. Moussa, "Phytosynthesis of selenium nanoparticles using the costus extract for bactericidal application against foodborne pathogens," Green Processing and Synthesis, vol. 9, no. 1, pp. 477-487, 2020.

[49] C. Ramamurthy, K. S. Sampath, P. Arunkumar et al., "Green synthesis and characterization of selenium nanoparticles and its augmented cytotoxicity with doxorubicin on cancer cells," Bioprocess and Biosystems Engineering, vol. 36, no. 8, pp. 1131-1139, 2013.

[50] G. Sharma, A. Sharma, R. Bhavesh et al., "Biomolecule-mediated synthesis of selenium nanoparticles using dried Vitis vinifera (raisin) extract," Molecules, vol. 19, no. 3, pp. 2761-2770, 2014.

[51] V. Ganesan, "Biogenic synthesis and characterization of selenium nanoparticles using the flower of Bougainvillea spectabilis Willd," International Journal of Science and Research, vol. 4, pp. 690-695, 2015.

[52] E. Cremonini, E. Zonaro, M. Donini et al., "Biogenic selenium nanoparticles: characterization, antimicrobial activity and effects on human dendritic cells and fibroblasts," Microbial Biotechnology, vol. 9, no. 6, pp. 758-771, 2016.

[53] H. M. Ahmed, A. M. Ramadhani, I. Y. Erwa, O. A. O. Ishag, and M. B. Saeed, "Phytochemical screening, chemical composition and antimicrobial activity of cinnamon verum bark," International Research Journal of Pure and Applied Chemistry, vol. 21, pp. 36-43, 2020.

[54] M. Moshaverinia, M. Rastegarfar, A. Moattari, and F. Lavaee, "Evaluation of the effect of hydro alcoholic extract of cinnamon on herpes simplex virus-1," Dental Research Journal, vol. 17, no. 2, p. 114, 2020.

[55] S. Anjum, G. Jacob, and B. Gupta, "Investigation of the herbal synthesis of silver nanoparticles using Cinnamon zeylanicum extract," Emergent Materials, vol. 2, no. 1, pp. 113-122, 2019.

[56] S. Mohapatra, L. Leelavathi, R. Adeep Kumar et al., "Assessment of antimicrobial efficacy of zinc oxide nanoparticles synthesized using clove and cinnamon formulation against oral pathogens-an in vitro study," Journal of Evolution of Medical and Dental Sciences, vol. 9, no. 29, pp. 2034-2039, 2020.

[57] T. M. Osaili, B. A. Albiss, A. A. Al-Nabulsi et al., "Effects of metal oxide nanoparticles with plant extract on viability of foodborne pathogens," Journal of Food Safety, vol. 39, no. 5, Article ID e12681, 2019.

[58] F. A. Alshubaily, "Enhanced antimycotic activity of nanoconjugates from fungal chitosan and Saussurea costus extract against resistant pathogenic Candida strains," International Journal of Biological Macromolecules, vol. 141, pp. 499-503, 2019.

[59] E. N. Danial, M. A. Elhalwagy, and N. O. Ayaz, "Phytochemical studies, antioxidant properties and antimicrobial activities of herbal medicinal plants costus and cidir used in Saudi Arabia," International Journal of Pharmacology, vol. 13, pp. 481-487, 2017.

[60] P. A. Tran and T. J. Webster, "Selenium nanoparticles inhibit Staphylococcus aureus growth," International Journal of Nanomedicine, vol. 6, pp. 1553-1558, 2011.

[61] L. Yan, Z. Gu, and Y. Zhao, "Chemical mechanisms of the toxicological properties of nanomaterials: generation of intracellular reactive oxygen species," Chemistry-An Asian Journal, vol. 8, no. 10, pp. 2342-2353, 2013.

[62] G. Zhao, X. Wu, P. Chen, L. Zhang, C. S. Yang, and J. Zhang, "Selenium nanoparticles are more efficient than sodium selenite in producing reactive oxygen species and hyper-accumulation of selenium nanoparticles in cancer cells generates potent therapeutic effects," Free Radical Biology and Medicine, vol. 126, pp. 55-66, 2018.

[63] A. Grigor'eva, I. Saranina, N. Tikunova et al., "Fine mechanisms of the interaction of silver nanoparticles with the cells of Salmonella typhimurium and Staphylococcus aureus," Biometals, vol. 26, pp. 479-488, 2013.

[64] X. Huang, X. Chen, Q. Chen, Q. Yu, D. Sun, and J. Liu, "Investigation of functional selenium nanoparticles as potent antimicrobial agents against superbugs," Acta Biomaterialia, vol. 30, pp. 397-407, 2016.

[65] G. Yuan, X. Chen, and D. Li, "Chitosan films and coatings containing essential oils: the antioxidant and antimicrobial activity, and application in food systems," Food Research International, vol. 89, pp. 117-128, 2016.

[66] A. K. Khare, R. J. Abraham, V. A. Rao, R. N. Babu, and W. Ruban, "Effect of Chitosan and Cinnamon oil edible coating on shelf life of chicken fillets under refrigeration conditions," Indian Journal of Animal Research, vol. 51, no. 3 , pp. 603-610, 2017. 